\title{
Getting it right is not equivalent to getting it wrong
}

\author{
Philip J. Stewart ${ }^{1}$
}

Published online: 19 May 2018

(C) The Author(s) 2018

\begin{abstract}
Mendeleev's successful predictions were the fruit of his insight into the structure of the periodic system. His failures were the result of pursuing the pattern he had perceived beyond the limits of its applicability. These two things are not equivalent.
\end{abstract}

Keywords Mendeleev $\cdot$ Periodic system $\cdot$ Predictions

I cannot agree with Wray in his comments on my paper ${ }^{1}$ that in my 'effort to justify discounting the weight of some of Mendeleev's failures', I invoke 'a principle that will, in turn, reduce the weight of some of the successful predictions'. ${ }^{2}$ Making a systematic mistake about one part of a system is not equivalent to getting most of the system right. I used the word 'serendipity', which was misleading; Mendeleev's alternation of periods of seven and eleven elements was an inspired insight into the structure of the periodic system, because $7+11=18$, the number of elements in the combined s, p and d blocks. His successful predictions were the fruit of this insight.

Mendeleev's failure to see that the 7/11 alternation was interrupted between barium and tantalum was excusable in 1871 , because not enough was known about the lanthanides. The alternation picked up again from tantalum to bismuth and seemed to continue in thorium and uranium, which he took to belong to his groups IV and VI. Indeed, in his 1922 table, Bohr still placed them in the d block. ${ }^{3}$ However, by 1904, Mendeleev should have seen that his failed predictions had atomic weights corresponding with 'rare earth' elements.

\footnotetext{
1 Stewart, P J, Mendeleev's Predictions: Success and Failure. FoCh 2018, pp. \#.

2 Wray, K B, 'What to Make of Mendeleev's predictions?' FoCh 2018 p. \#.

3 https://www.meta-synthesis.com/webbook/35_pt/pt_database.php?PT_id=285. Accessed 09/05/2018.
}

Philip J. Stewart

philip.stewart@plants.ox.ac.uk

1 University of Oxford, Oxford, UK 
I accept that Scerri's 'score card' was part of a different argument, but it was nevertheless a rating of predictions and it concluded that half of them were wrong. ${ }^{4}$ I stick by my weighting, which suggests that they were predominantly successful.

Open Access This article is distributed under the terms of the Creative Commons Attribution 4.0 International License (http://creativecommons.org/licenses/by/4.0/), which permits unrestricted use, distribution, and reproduction in any medium, provided you give appropriate credit to the original author(s) and the source, provide a link to the Creative Commons license, and indicate if changes were made.

${ }^{4}$ Scerri, E R, The Periodic Table: its Story and Significance, Oxfod University Press, 2007, pp 142-143. 